\title{
A New Insensitive Explosive That Has Moderate Performance and is Low Cost: 2, 4-Dinitroimidazole
}

R. Simpson

C. Coon

M. Foltz

P. Pagoria

January 1995

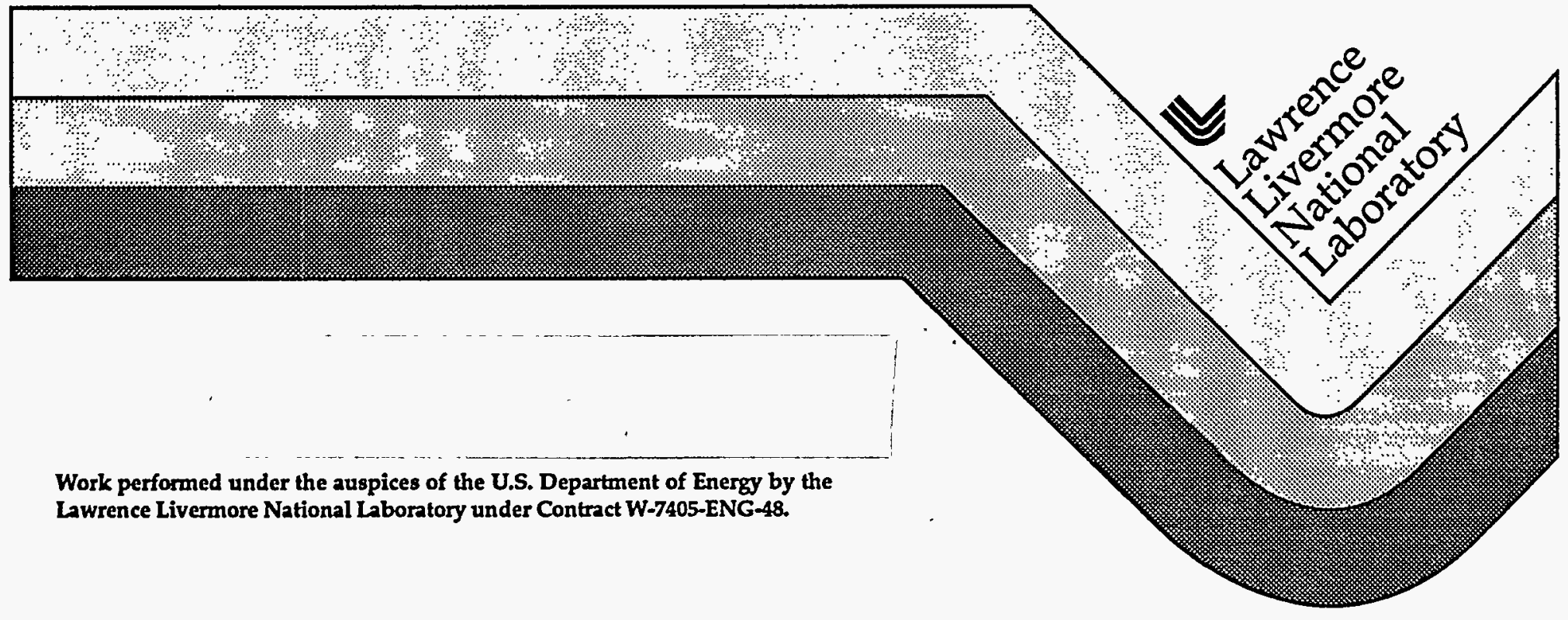




\section{DISCLAIMER}

This document was prepared as an account of work sponsored by an agency of the United States Government. Neither the United States Government nor the University of California nor any of their employees, makes any warranty, express or implied, or assumes any legal liability or responsibility for the accuracy, completeness, or usefulness of any information, apparatus, product, or process disclosed, or represents that its use would not infringe privately owned rights. Reference herein to any specific commercial product, process, or service by trade name, trademark, manufacturer, or otherwise, does not necessarily constitute or imply its endorsement, recommendation, or favoring by the United States Government or the University of California. The views and opinions of authors expressed herein do not necessarily state or reflect those of the United States Covernment or the University of California, and shall not be used for advertising or product endorsement purposes.

This report has been reproduced directly from the best available copy.

Available to DOE and DOE contractors from the Office of Scientific and Technical Information

P.O. Box 62, Oak Ridge, TN 37831

Prices available from (615) 576-8401, FTS 626-8401

Available to the public from the National Technical Information Service

U.S. Department of Commerce 5285 Port Royal Rd. Springfield, VA 22161 


\section{DISCLAIMER}

Portions of this document may be illegible in electronic image products. Images are produced from the best available original document. 


\title{
A New Insensitive Explosive That Has Moderate Performance and is Low Cost: 2, 4-Dinitroimidazole
}

\author{
R.L. Simpson, C.L. Coon, M.F. Foltz and P.F. Pagoria \\ Energetic Materials Center \\ Lawrence Livermore National Laboratory
}

\section{Summary}

2, 4-dinitroimidazole is a very shock insensitive material. The performance of the material is expected to be $60 \%$ greater than TNT. Costs appear to be low but are unresolved at this time. 2, 4-DNI may be a realistic alternative to TNT for mass-use bombs.

\section{Introduction}

LLNL is working together with the Army at ARDEC and the Los Alamos National Laboratory (LANL) in synthesizing and characterizing the energetic molecule 2, 4-DNI. For many mass-use applications 2, 4-DNI appears to be the best compromise of properties. TNT is less expensive, HMX has higher performance, PETN has hotter detonation products, and TATB is less sensitive than 2, 4-DNI. However, 2, 4-DNI appears to beat them all in terms of a property compromise for real world applications.

The cooperative activity is described in the following joint LLNLLANL-ARMY report. What is reported here are the results of recent shock loading studies, performance calculations, and sensitivity discussion.

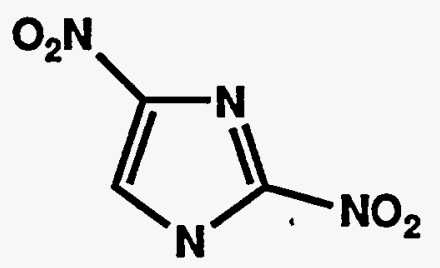

\section{2,4-DNI}

Shock Loading

We have performed three shock loading experiments on a 2, 4-DNI-based formulation RX51AA. The formulation consists of $95.0 \mathrm{wt} \% 2,4-\mathrm{DNI}$ and 5.0\% Estane-5702. This material approximates the DOE/DoD HMX-based explosive LX-14 (95.5wt\%HMX, 4.5\% 
Estane). RX51AA was pressed to a nominal density of $96.6 \%$ of theoretical maximum density (TMD). It should be noted that LX-14 has a higher nominal density of $97.3 \%$ TMD, and $0.5 \%$ less explosive by volume than RX51AA. These differences are expected to make RX51AA slightly more sensitive than a 2,4-DNI-based material that was an exact match to LX-14.

The shock loading configuration is shown in Fig. 1. A smooth $100 \mathrm{~mm}$ bore powder gun was used to one-dimensionally shock the samples. Six in situ manganin pressure gauges were located at three different depths in the explosive. Pressure histories as a function of time are obtained at each location.

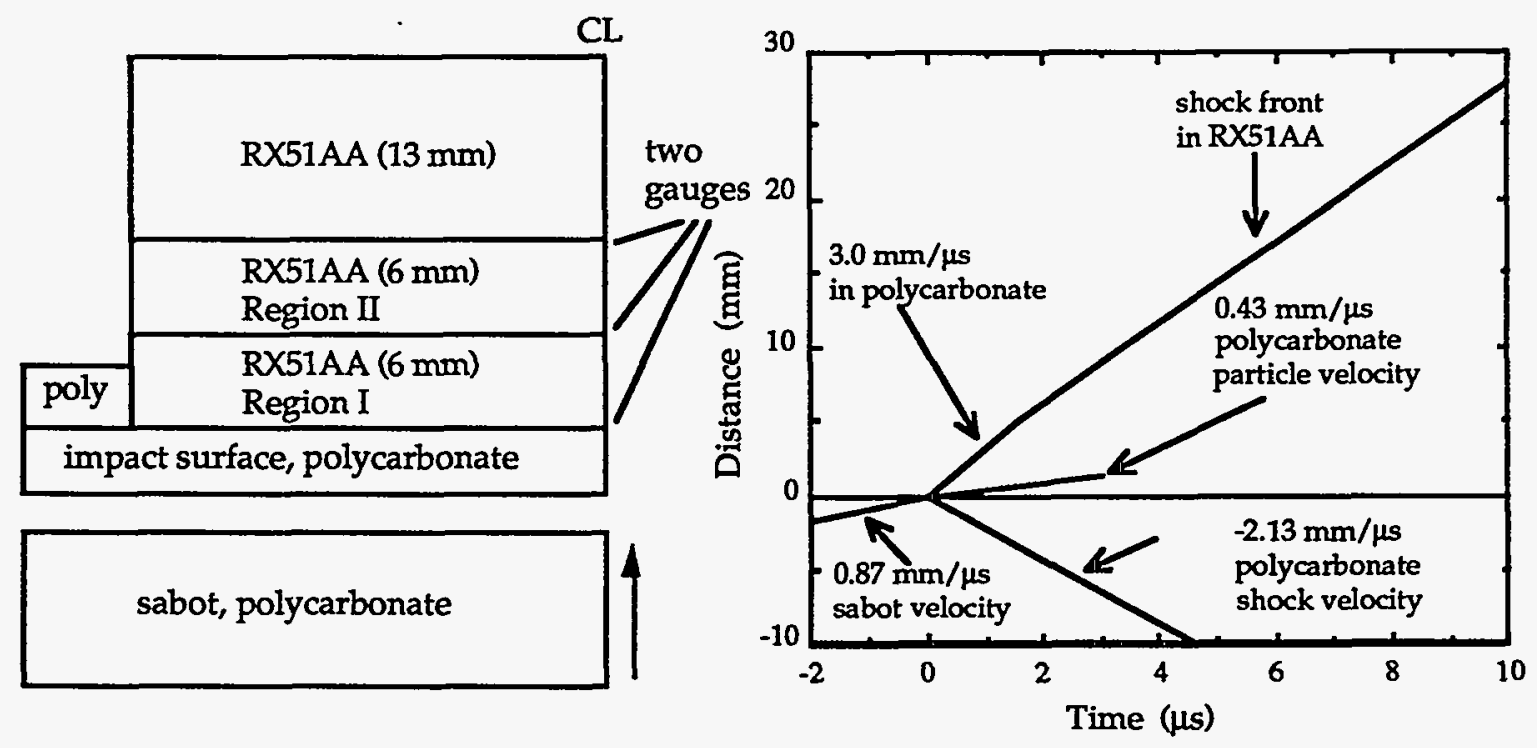

Figure 1. Experimental configuration and shock trajectory plot.

The experiment data are shown in Fig. 2. Figure 2a displays the pressure response of LX-14 at an input pressure of $22.7 \mathrm{kbar}$ at: $0 \mathrm{~mm}, 6 \mathrm{~mm}$, and $13 \mathrm{~mm}$. As can be seen LX-14 has nearly transitioned to detonation after the shock has run $13 \mathrm{~mm}$. At approximately the same shock pressure, the 2, 4-DNI-based material shows no reaction. In fact the shock velocity is actually decreasing. Table 1 lists the shock velocities between the different gauge stations for the three samples.

Nearly doubling the shock input pressure to $38.3 \mathrm{kbar}$ is adequate to begin to initiate $\mathrm{R} \times 51 \mathrm{AA}$. The reactions are slow and the shock front is only slightly accelerating. A typical high solids loaded plastic bonded explosive would show a prompt transition under these conditions. It should be noted that the oscillations in the first pressure 
signal in Fig. $2 c$ were due to the power supply of the gauge not being stabilized at the time of the shock arrival and is not a material response.

At $72 \mathrm{kbar}$ the material has nearly transitioned to detonation $6 \mathrm{~mm}$ into the sample. The shock velocity between $6 \mathrm{~mm}$ and $13 \mathrm{~mm}$ is consistent with steady state detonation.

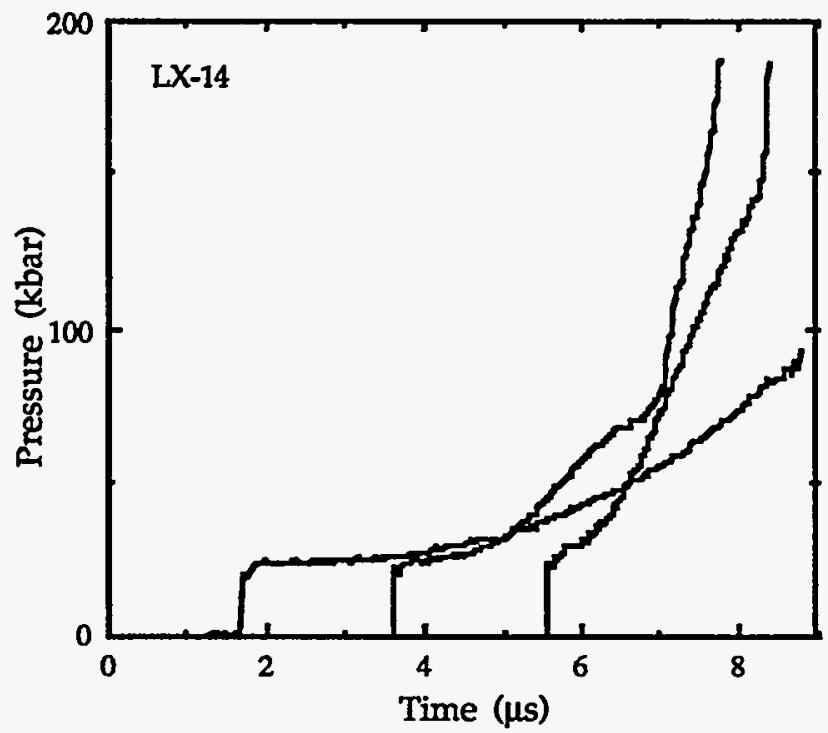

(a)

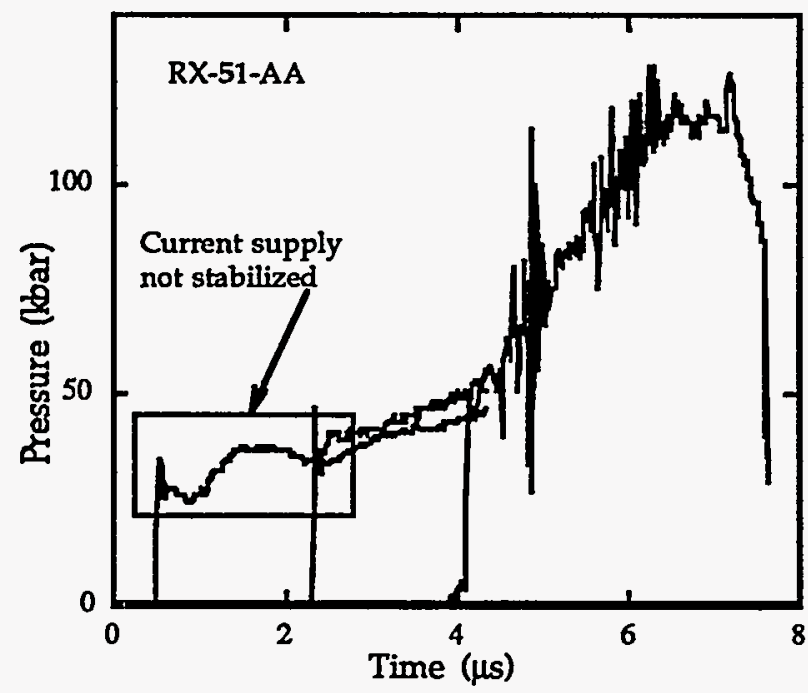

(c)

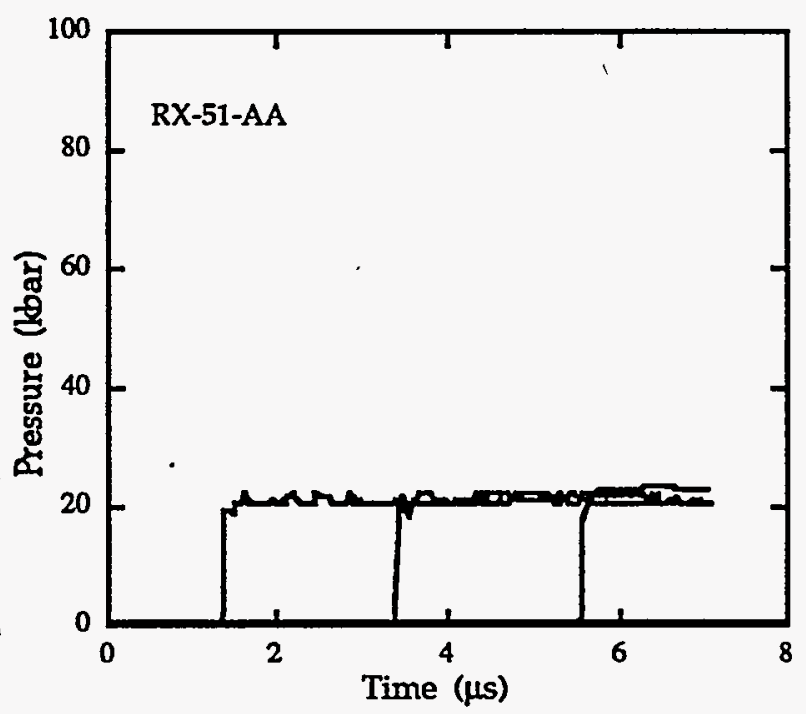

(b)

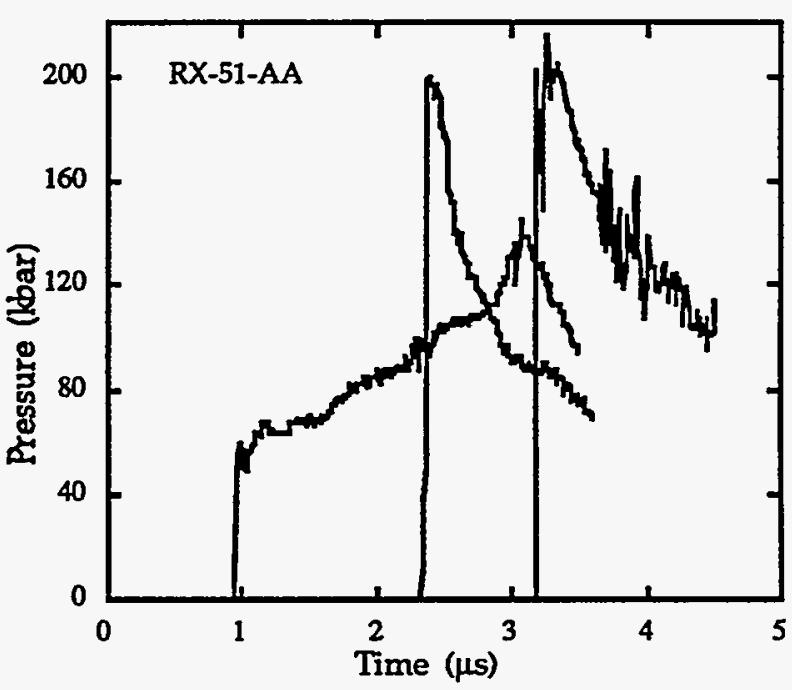

(d)

Figure 2. Pressure histories of: (a) LX-14 shocked at 22.7 kbar. (b) RX51AA shocked at 21.0 kbar. (c) RX51AA shocked at 38.3 kbar. (d) RX51AA shocked at $72 \mathrm{kbar}$. 
Table 1. Shock velocity histories in RX51AA.

\begin{tabular}{|c|c|c|l|}
\hline \hline $\begin{array}{c}\text { Shock Loading } \\
\text { Pressure (kbar) }\end{array}$ & $\begin{array}{c}\text { Region I } \\
(\mathrm{mm} / \mu \mathrm{s})\end{array}$ & $\begin{array}{c}\text { Region II } \\
(\mathrm{mm} / \mu \mathrm{s})\end{array}$ & Behavior \\
\hline \hline 2.10 & 2.96 & 2.79 & decrease \\
\hline 3.83 & 3.51 & 3.58 & same \\
\hline 7.0 & 4.59 & 8.00 & transitioned \\
\hline \hline
\end{tabular}

\section{Performance of 2, 4-DNI}

Table 2 lists the predicted performance of 2, 4-DNI compared to TNT. It can be seen that 2, 4-DNI is significantly better. As described in the following joint LLNL-LANLARDEC paper the detonation products appear to be very hot suggesting utility in nonideal composite explosives.

Table 2. Explosive performance of 2, 4-DNI.

\begin{tabular}{|l|c|c|c|c|}
\hline \hline \multicolumn{2}{|c|}{ Detonation Parameters } & \multicolumn{3}{c|}{ Predicted Energy } \\
\hline$\rho(\mathrm{g} / \mathrm{cc})$ & 1.76 & $\mathrm{~V} / \mathrm{V}_{\mathrm{O}}$ & $\begin{array}{c}\text { Relative to } \\
\text { TNT }\end{array}$ & $\begin{array}{c}\text { Relative to } \\
\text { HMX }\end{array}$ \\
\hline $\mathrm{D}(\mathrm{mm} / \mu \mathrm{s})$ & 7.961 & 2.2 & +49 & -27 \\
\hline $\mathrm{u}_{\mathrm{p}}(\mathrm{mm} / \mu \mathrm{s})$ & 2.02 & 4.1 & +56 & -26 \\
\hline $\mathrm{P}_{\mathrm{CI}}(\mathrm{GPa})$ & 27.8 & 6.5 & +59 & -26 \\
\hline $\mathrm{V}_{\mathrm{CJ}}(\mathrm{cc} / \mathrm{g})$ & 0.424 & 10 & & -25 \\
\hline $\mathrm{T}_{\mathrm{CI}}(\mathrm{K})$ & 3130 & 20 & & -25 \\
\hline $\mathrm{E}_{\mathrm{CJ}}(\mathrm{cal} / \mathrm{g})$ & 485 & \multicolumn{4}{|l}{} \\
\hline \hline
\end{tabular}

We have evaluated 2, 4-DNI for propellant applications. Although attractive as a high explosive it appears not to be of value as a propellant component. Table 3 summarizes the propulsion properties of pure 2, 4-DNI. It can be seen that the specific impulse ( $\left.\mathrm{I}_{\mathrm{sp}}\right)$ is significantly below HMX and 1,3,3-trinitroazetidine (TNAZ). Tables $3 \& 4$ list the calculated performance of strategic and tactical propellants based on 2, 4-DNI. It is clear that there are no performance benefits with 2, 4-DNI for these propellant applications. 
Table 3. $\mathrm{I}_{\text {sp }}$ of pure materials.

\begin{tabular}{|l|c|c|c|c|c|c|}
\hline \multirow{2}{*}{ Material } & \multicolumn{2}{|c|}{ HMX } & \multicolumn{2}{c|}{ TNAZ } & \multicolumn{2}{c|}{ 2,4-DNI } \\
\cline { 2 - 7 } & Chmb & Exh & Chmb & Exh & Chmb & Exh \\
\hline \hline P (psia) & 1000 & 14.7 & 1000 & 14.7 & 1000 & 14.7 \\
\hline Expansion ratio & & 8.36 & & 9.15 & & 7.86 \\
\hline Isp @ atms & & $\underline{265}$ & & $\underline{273}$ & & $\underline{237}$ \\
\hline Isp @ vacuum & & 286 & & 296 & & 254 \\
\hline T (K) & 3276 & 1557 & 3522 & 1973 & 2992 & 1262 \\
\hline Mw & 24.27 & 24.68 & 26.16 & 27.43 & 26.24 & 26.35 \\
\hline Mols gas/100 g & 4.12 & 4.05 & 3.82 & 3.64 & 3.81 & 3.80 \\
\hline C $^{*}$ (ft/sec) & 5389 & & 5442 & & 4871 & \\
\hline \hline
\end{tabular}

Table 4. Performance as a Class 1.1 aluminized propellant.

\begin{tabular}{|l|c|c|c|c|c|c|}
\hline \hline \multirow{2}{*}{ Material } & \multicolumn{2}{|c|}{ HMX-based } & \multicolumn{2}{c|}{ TNAZ-based } & 2,4-DNI-based \\
\cline { 2 - 7 } & Chmb & Exh & Chmb & Exh & Chmb & Exh \\
\hline \hline P (psia) & 1000 & 14.7 & 1000 & 14.7 & 1000 & 14.7 \\
\hline Expansion ratio & & 10.13 & & 10.10 & & 10.31 \\
\hline Isp @ atms & & $\underline{273}$ & & $\underline{274}$ & & $\underline{259}$ \\
\hline Isp @ vacuum & & 298 & & 299 & & 283 \\
\hline T (K) & 3706 & 2327 & 3853 & 2454 & 3475 & 2183 \\
\hline Mw & 28.36 & 29.58 & 29.59 & 31.20 & 29.33 & 30.35 \\
\hline Mols gas/100 g & 3.53 & 3.38 & 3.38 & 3.20 & 3.41 & 3.3 \\
\hline$C^{*}(\mathrm{ft} / \mathrm{sec})$ & 5381 & & 5380 & & 5104 & \\
\hline \hline
\end{tabular}

Table 5. Performance as a smokeless propellant (70/20/10 oxidizer/NG/NEPE).

\begin{tabular}{|c|c|c|c|c|c|c|c|c|c|c|c|c|}
\hline \multirow[t]{2}{*}{ Material } & \multicolumn{4}{|c|}{$\overline{\text { FMX-based }}$} & \multicolumn{4}{|c|}{ TNAZ-based } & \multicolumn{4}{|c|}{ 2,4-DNI-based } \\
\hline & $\mathrm{Chm}$ & Exh & Exh & $\overline{E x h}$ & $\mathrm{Chm}$ & Exh & $\overline{E x h}$ & Exh & $\mathrm{Chb}$ & $\overline{\text { Exh }}$ & Exh & $\overline{\mathrm{Exh}}$ \\
\hline$\overline{P \text { (psia) }}$ & 1000 & 14.7 & $\overline{5.8}$ & 2.3 & 1000 & $\overline{14.7}$ & 6.056 & 2.424 & 1000 & 14.7 & $\overline{5.66}$ & 2.50 \\
\hline Expansion ratio & & 8 & 16 & 32 & & 8 & 16 & 32 & & 8 & 16 & 32 \\
\hline Isp@atms & & $2 \underline{255}$ & 271 & 283 & & $\underline{263}$ & $\underline{279}$ & 293 & & $\underline{233}$ & $\underline{248}$ & $\underline{258}$ \\
\hline Isp@ vacuum & & $\overline{274}$ & 286 & 295 & & $\overline{284}$ & $\overline{295}$ & $\overline{305}$ & & 250 & $\overline{261}$ & 270 \\
\hline $\mathrm{T}(\mathrm{K})$ & 2945 & 1292 & 1073 & 903 & 3233 & 1514 & 1273 & 1068 & 2658 & 1098 & 931 & 881 \\
\hline$\overline{M w}$ & 22.73 & 22.84 & 22.84 & 22.87 & 24.12 & 24.43 & 24.43 & 24.43 & 23.78 & 23.83 & 24.07 & 24.7 \\
\hline Mols gas $/ 100 \mathrm{~g}$ & 4.40 & 4.38 & 4.38 & 4.37 & 4.15 & 4.09 & 4.09 & 4.09 & 4.2 & 4.2 & 4.15 & 4.05 \\
\hline $\mathrm{C}^{*}(\mathrm{ft} / \mathrm{sec})$ & 5216 & & & & 5356 & & & & 4801 & & & \\
\hline
\end{tabular}




\section{Impact Sensitivity}

Major differences in the impact sensitivity of 2, 4-DNI have been observed depending on the purity of the material. Unlike most materials the impact sensitivity increases with purity. Coburn, of LANL, has observed a correlation in sensitivity with the concentration of 4-nitroimidazole (4-NI).

We are examining this phenomenon in terms of crystal structure. The crystal structures for 2, 4-DNI and 4-NI are shown in Fig. 3. A crystal of 2, 4-DNI consists of ribbons of molecules. The hydrogen bonding network in 4-NI is similar, but it has totally planar packing resulting from extra $\mathrm{H}$-bonds. 4-NI inclusions may stabilize the otherwise unstable 2, 4-DNI polymorphic structure as is shown in Fig. 3c.

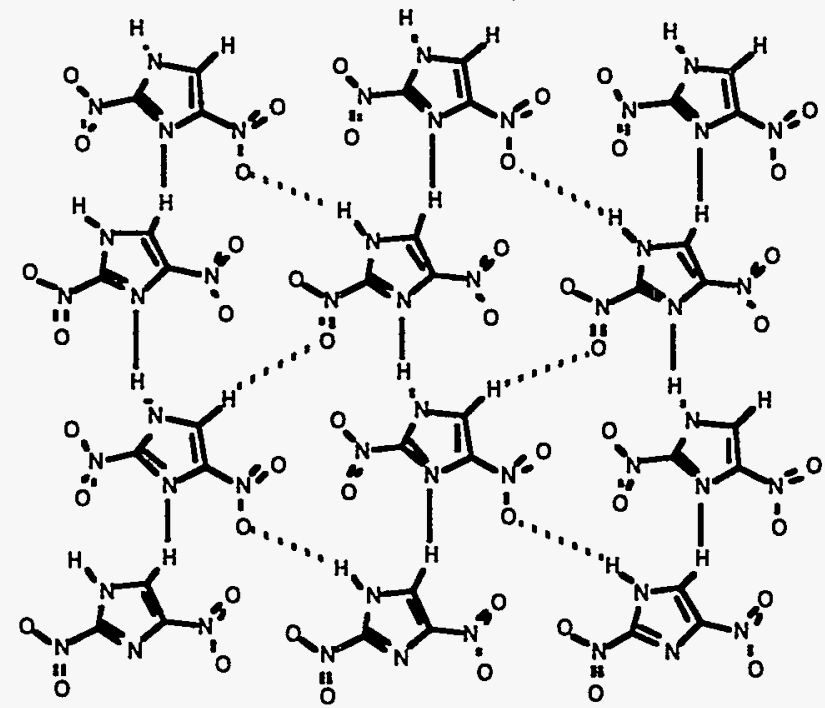

(a)

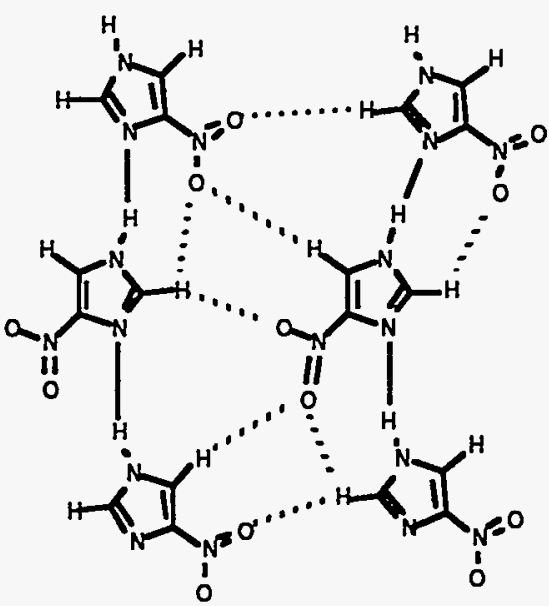

(b)

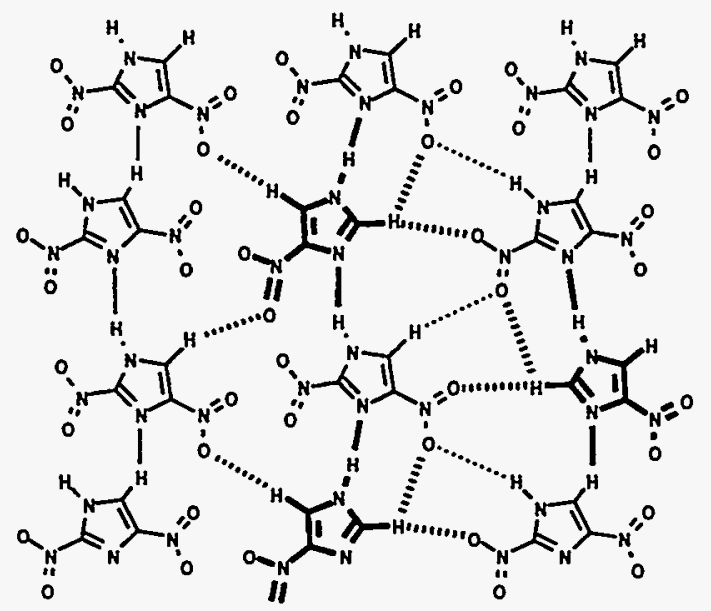

(c)

Figure 3. (a) 2, 4-DNI non-planar crystal. (b) 4-NI planar crystal. (c) Postulated planar 2, 4-DNI + 4-NI planar crystal. 
This phenomenon is being examined more closely. Although it is unlikely that the presence of 4-NI will effect the shock sensitivity of 2, 4-DNI, its inclusion may dramatically enhance the handling safety.

\section{Conclusions and Future Directions}

The shock loading studies on 2, 4-DNI have found the material to be less sensitive than any other conventional bonded explosives that we have made measurements on with the exception TATB-based materials. 2, 4-DNI significantly outperforms TNT. What remains to be done is an accurate determination of production costs. We are in the process of optimizing the synthesis of the material. We plan to scale 2, 4-DNI to a $5 \mathrm{~kg}$ quantity this year.

The 2, 4-DNI will be made available to other DoD/DOE laboratories. We are also evaluating the utility of 2, 4-DNI in the joint LLNL-Air Force Hard Structure Munitions High Explosive Program. 